\title{
Exploring metabolic adaptation of Streptococcus pneumoniae to antibiotics
}

\author{
Anne Leonard ${ }^{1} \cdot$ Kevin Möhlis $^{1} \cdot$ Rabea Schlüter $^{2} \cdot$ Edward Taylor $^{3} \cdot$ Michael Lalk $^{1} \cdot$ Karen Methling $^{1}$
}

Received: 4 October 2019 / Revised: 31 January 2020 / Accepted: 9 February 2020 / Published online: 24 March 2020

(c) The Author(s) 2020. This article is published with open access

\begin{abstract}
The Gram-positive bacterium Streptococcus pneumoniae is one of the common causes of community acquired pneumonia, meningitis, and otitis media. Analyzing the metabolic adaptation toward environmental stress conditions improves our understanding of its pathophysiology and its dependency on host-derived nutrients. In this study, extra- and intracellular metabolic profiles were evaluated to investigate the impact of antimicrobial compounds targeting different pathways of the metabolome of $S$. pneumoniae TIGR $4 \Delta c$ s. For the metabolomics approach, we analyzed the complex variety of metabolites by using ${ }^{1} \mathrm{H}$ NMR, HPLC-MS, and GC-MS as different analytical techniques. Through this combination, we detected nearly 120 metabolites. For each antimicrobial compound, individual metabolic effects were detected that often comprised global biosynthetic pathways. Cefotaxime altered amino acids metabolism and carbon metabolism. The purine and pyrimidine metabolic pathways were mostly affected by moxifloxacin treatment. The combination of cefotaxime and azithromycin intensified the stress response compared with the use of the single antibiotic. However, we observed that three cell wall metabolites were altered only by treatment with the combination of the two antibiotics. Only moxifloxacin stressinduced alternation in CDP-ribitol concentration. Teixobactin-Arg10 resulted in global changes of pneumococcal metabolism. To meet the growing requirements for new antibiotics, our metabolomics approach has shown to be a promising complement to other OMICs investigations allowing insights into the mode of action of novel antimicrobial compounds.
\end{abstract}

\section{Introduction}

In community-acquired pneumonia (CAP), a serious illness associated with morbidity and mortality [1-4], the most frequent pathogen isolated in adults is Streptococcus pneumoniae (the pneumococcus) [5, 6]. S. pneumoniae, a Gram-positive facultative pathobiont, commonly inhabits

Supplementary information The online version of this article (https:// doi.org/10.1038/s41429-020-0296-3) contains supplementary material, which is available to authorized users.

Karen Methling

methling@uni-greifswald.de

1 Institute for Biochemistry, Metabolomics, University of Greifswald, Felix-Hausdorff-Str. 4, 17489 Greifswald, Germany

2 Imaging Center of the Department of Biology, University of Greifswald, F.-L-Jahn-Str. 15, 17489 Greifswald, Germany

3 University of Lincoln, School of Life Sciences, Green Lane, LN67DL Lincoln, England, United Kingdom the upper respiratory tract of humans and resulting in at least 1-2 million infant deaths every year worldwide $[4,7,8]$. The pneumococcus is a fermentative bacterium with a high rate of glycolysis [9] and lacks of the EntnerDoudoroff pathway, aerobic tricarboxylic acid cycle, and the electron transport chain of aerobe and anaerobe respiration [9-11]. A challenge in treating pneumococcal infections is the increasing drug resistance over recent decades. Currently, 15-30\% of the pneumococcal strains are classified as multi drug resistant [12]. Due to the side effects of fluoroquinolones the European Medicines Agency for Europe has emulated the U.S. Food and Drug Administration in introducing restrictions on their use. Typical antibiotic therapies of pneumococcus include $\beta$-lactams, macrolides, or fluoroquinolones alone or in combination. The use of combination therapy of two antibiotics has been shown to achieve superior outcome compared with monotherapy [13-16].

Moxifloxacin is a recently-developed fluoroquinolone that acts by binding to the topoisomerase enzymes II (DNA gyrase) thus preventing replication, transcription, and repair 
of bacterial DNA [17]. S. pneumoniae appears to be less resistant to 8-methoxy quinolone moxifloxacin compared with earlier fluoroquinolones [18].

The cephalosporins are a group of $\beta$-lactam antibiotics. With a mode of action comparable to penicillin, inhibiting cell wall synthesis and modification by binding penicillinbinding proteins (PBPs), this results in arrest of cell growth and eventual cell lysis of bacteria. PBPs are membraneassociated enzymes involved in the final step of peptidoglycan assembly and turnover [19]. Penicillin allergy is the most common drug allergy concerning up to $15 \%$ of hospitalized patients, which can present a barrier to treatment of S. pneumoniae infections [20]. Cephalosporines like cefotaxime were developed to face bacteria resistant to penicillin or treat infections in humans allergic to penicillin [21]. Cefotaxime is rapidly deacetylated in the body to desacetyl cefotaxime, which has a similar antimicrobial spectrum to cefotaxime [21].

Azithromycin is a macrolide derivative of erythromycin. The azolide antimicrobial agent is active against pathogens responsible for infections of the respiratory tract, skin, and soft tissues in human [22]. Azithromycin inhibits bacterial growth and replication by interrupting protein biosynthesis [23].

S. pneumoniae has repeatedly been shown to be capable of rapidly developing or acquiring resistance to the commonly used agents of treating pneumonia. The use of antibiotic combinations increases the spectrum of targeted bacterial species in addition to increased efficacy, limiting the occurrence and spread of resistant bacterial populations. Many studies focused on the combination of a cephalosporin and a macrolide [6, 15, 16, 24, 25].

The rapid development of bacterial resistance to antibiotics is one of the most recent threats to human health [26]. In the last 40 years only two new classes of antibiotics have been discovered [27]. In 2015, the organism, Eleftheria terrae, was found to produce a novel depsipeptide antibiotic, called teixobactin [28]. The antibiotic kills a broad range of Grampositive bacteria including multi drug resistance strains [28]. There is currently no evidence of acquired resistance. Teixobactin binds to the pyrophosphate motifs of multiple bacterial cell-wall substrates such as lipid II (precursor of peptidoglycan) and lipid III (precursor of cell-wall teichoic acid) [28]. Teixobactin is a naturally occurring molecule and has a number of issues preventing direct introduction to the clinic [28, 29]. Parmar et al. designed a synthesis of teixobactin analogs that sacrifices antibiotic activity for ease of synthesis through the replacement of the difficulty to synthesize enduracididine with arginine [29].

Understanding the metabolism of pneumococci is essential to gain insights into the adaptation strategies that are required to deal with the host environment during infection and to identify new drug targets [30]. We analyzed the metabolic response of $S$. pneumoniae to limited growth conditions as well as during treatment with antimicrobial compounds to identify metabolic adaptation processes. This study will contribute to a better understanding of pneumococcal physiology. We have used our recently established workflow [9] to analyze the alterations of extra- and intracellular metabolites of $S$. pneumoniae after treatment with different antimicrobial compounds. To cover a broad range of metabolic adaptations, pneumococci were exposed to three commonly used antibiotics with different targets of action (cefotaxime, azithromycin, and moxifloxacin), a combination of two antibiotics (cefotaxime and azithromycin), and the new antimicrobial compound (teixobactin-Arg 10 [29]).

\section{Material and methods}

\section{Bacterial strain and growth conditions}

The non-encapsulated S. pneumoniae TIGR4 4 cps used as model organism was cultivated in the chemically-defined medium RPMI modi 1640 (HyClone) [9] and grown on Columbia blood agar plates (Oxoid) in the presence of the appropriate antibiotic $\left(150 \mu \mathrm{g} \mathrm{ml}^{-1}\right.$ kanamycin $)$. The cultivation was performed as described previously [9]. At a midexponential phase $\mathrm{OD}_{600}$ of 0.5 the bacterial cells were treated with either $0.005 \mu \mathrm{g} \mathrm{ml}^{-1}(0.5 \times$ minimal inhibitor concentration (MIC)) cefotaxime (Sigma-Aldrich), $0.064 \mu \mathrm{g} \mathrm{ml}^{-1}(2 \times \mathrm{MIC})$ azithromycin (Sigma-Aldrich), $0.8 \mu \mathrm{g} \mathrm{ml}^{-1} \quad(2 \times \mathrm{MIC})$ moxifloxacin (Sigma-Aldrich), $2 \mu \mathrm{g} \mathrm{ml}^{-1}$ teixobactin-Arg10 (cooperation with University of Lincoln, School of Life Sciences [31, 32]), and combination of $0.5 \times$ MIC cefotaxime and $2 \times$ MIC azithromycin for $90 \mathrm{~min}$. For the control, bacterial cells were cultivated without antibiotic. We obtained five independent biological replicates for the metabolome analysis with exception of teixobactin analog (four independent biological replicates). Extra- and intracellular metabolome samples were taken at $15,30,60$, and $90 \min \left(\mathrm{t}_{15}, \mathrm{t}_{30}, \mathrm{t}_{60}\right.$, and $\left.\mathrm{t}_{90}\right)$ after the addition of each antimicrobial compound.

\section{Minimal inhibitory concentration (MIC)}

MIC is defined as lowest concentration of a compound/ drug/antibiotic preventing visible growth of a microorganism [33]. The MIC for each antibiotic compounds was determined for $S$. pneumoniae TIGR4 4 cps cultivated in modified RPMI medium $(n=3)$. The MIC determination for teixobactin analog was tested only once due to available restricted amount of compound. At an $\mathrm{OD}_{600}$ of 0.1 each antibiotic was added to the bacterial main culture in dilution series. At every hour, the $\mathrm{OD}_{600}$ was measured for $6 \mathrm{~h}$. 


\section{Preparation and ${ }^{1} \mathrm{H}$ NMR spectroscopic analysis of extracellular metabolites}

For the analysis of extracellular metabolites, $2 \mathrm{ml}$ bacterial cell suspension was filtered and analyzed by using ${ }^{1} \mathrm{H}$ Nuclear Magnetic Resonance ( ${ }^{1} \mathrm{H}$ NMR) spectroscopy as described previously [9].

\section{Preparation of intracellular metabolite extracts}

The sampling of intracellular metabolites was described earlier [9]. In brief, 15 OD units (1 OD units equates $1 \mathrm{ml}$ at $\mathrm{OD}_{600 \mathrm{~nm}}$ of 1) were sampled by using the vacuumdependent fast-filtration approach. The filtered cells were washed twice with $5 \mathrm{ml}$ cold isotonic sodium chloride solution $(130 \mathrm{mM})$. After the transfer of the filter into extraction solution $(60 \%$ ethanol $[\mathrm{w} / \mathrm{v}])$, the samples were shock frozen (liquid $\mathrm{N}_{2}$ ) and stored at $-80{ }^{\circ} \mathrm{C}$ prior extraction. To obtain the intracellular metabolite extracts, the bacterial cells were washed off the filter by shaking and vortexing. Resuspended bacteria were transferred into a 50 $\mathrm{ml}$ tube containing glass beads with $0.1 \mathrm{~mm}$ diameter (Sartorius AG). The internal standards (see Supplementary Table S1) for LC-MS and GC-MS analyses were added. Two cell disruption cycles $(2 \times 40 \mathrm{~s}, 6.0 \mathrm{~m} / \mathrm{s})$ were performed by using the FastPrep-24 instrument (MP Biomedicals). The transfer, washing, and centrifugation of the bacterial cell extract were described earlier [9]. The supernatant was diluted with water and stored at $-80^{\circ} \mathrm{C}$ for lyophilization. The dried samples were resuspended in $1.5 \mathrm{ml}$ cold water and divided into two equal parts. One part of each sample was directly frozen and lyophilized for further GC-MS analysis. $150 \mu \mathrm{l}$ ice-cold trichloromethane was added to the other part of the samples. After shaking and vortexing for ten times the samples were stored at $-20{ }^{\circ} \mathrm{C}$ for $5 \mathrm{~min}$ and centrifuged at $4{ }^{\circ} \mathrm{C}$ and $13,000 \mathrm{rpm}$ for $5 \mathrm{~min}$. The upper layer of each sample was collected, frozen, and lyophilized for LC-MS analysis.

\section{HPLC-MS and GC-MS analyses}

The measurements of the lyophilized extracts with LC-MS and GC-MS according to the protocol are described elsewhere [9].

The qualitative and quantitative analyses of LC-MS data were carried out by using DataAnalysis v4.0 and QuantAnalysis v2.0 software (Bruker Daltonik $\mathrm{GmbH}$ ). Absolute concentrations of metabolites were determined using calibration curves for each metabolite (see Supplementary Table S2). Signals detected in blank samples were excluded from the data analysis of biological samples.

For the GC-MS analysis, the identification and quantification of intracellular metabolites were performed using MassHunter (Agilent). Identification of peaks was carried out by comparison of retention time and mass spectra with those of standard compounds in a database with a similarity of $75 \%$ or higher. For quantification, the areas of the identified peaks were normalized to the area of peaks of internal standard compounds (see Supplementary Table S2). This ratio represented the relative amount of each metabolite. Absolute concentrations of metabolites were determined using calibration curves for each metabolite. Signals detected in blank samples were excluded from the data analysis of biological samples.

\section{Determination of the adenylate energy charge}

Adenylate energy charge (AEC) was calculated for each sample using the absolute concentrations of AMP, ADP, and ATP [34].

\section{Colony forming units (CFU)}

Pneumococci were cultivated as described in the cultivation section above. At $t_{30}$ and $t_{90}$ after adding antibiotics, $50 \mu$ of each culture was transferred into a $1.5 \mathrm{ml}$ micro-reaction tube that contained $950 \mu \mathrm{l}$ modified RPMI medium. The tube was gently swung to ensure an equal dilution. The dilution step was repeated four times until a dilution factor of $3.2 \times 10^{6}$ was reached. $50 \mu$ of the final dilution was spread equally with an inoculation spreader on a blood agar plate and incubated for $20 \mathrm{~h}\left(37^{\circ} \mathrm{C} / 5 \% \mathrm{CO}_{2}\right)$. After $20 \mathrm{~h}$, the colonies were counted.

\section{Transmission electron microscopy}

For the transmission electron microscopy (TEM), 15 OD units were transferred into a $50 \mathrm{ml}$ tube at $t_{90}$ and centrifugated carefully $\left(3000 \mathrm{rpm}, 20^{\circ} \mathrm{C}, 3 \mathrm{~min}\right)$. The pellet was washed with $10 \mathrm{ml}$ isotonic $\mathrm{NaCl}$ solution and centrifuged again. The cells were fixed with a solution containing $2.5 \%$ glutaraldehyde and $2 \%$ paraformaldehyde in buffer $\left(100 \mathrm{mM}\right.$ cacodylate buffer, $10 \mathrm{mM} \mathrm{CaCl}_{2}, 10 \mathrm{mM}$ $\mathrm{MgCl}_{2}, 0.09 \mathrm{M}$ sucrose; $\mathrm{pH} 7$ ) for $20 \mathrm{~min}$ on ice and then stored at $4{ }^{\circ} \mathrm{C}$ until further processing using two different methods. For method A, cells were embedded in low gelling agarose, post fixed in $1 \%$ osmium tetroxide in buffer for $1 \mathrm{~h}$, and then stained en bloc with $2 \%$ uranyl acetate in $0.9 \%$ sodium chloride for $30 \mathrm{~min}$ at room temperature. For method B, cells were treated with $0.5 \%$ glutaraldehyde and $1 \%$ osmium tetroxide in buffer for $1 \mathrm{~h}$ at $4{ }^{\circ} \mathrm{C}$. Subsequent to embedding in low gelling agarose, cells were fixed with $1 \%$ osmium tetroxide in buffer for $1 \mathrm{~h}$ at room temperature, and then stained en bloc with $0.5 \%$ uranyl acetate in $0.9 \%$ sodium chloride at $4{ }^{\circ} \mathrm{C}$ overnight. 


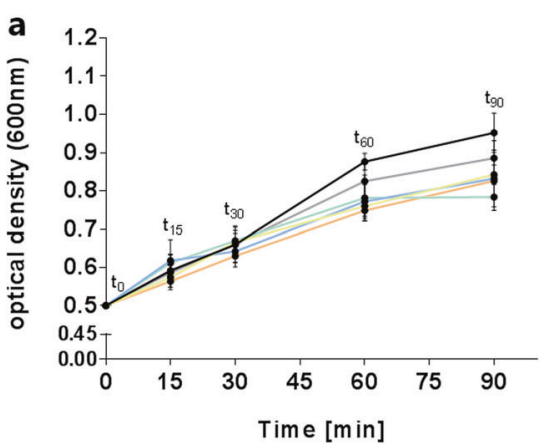

Fig. 1 Growth curves (a) of $S$. pneumoniae TIGR4 4 cps in $\mathrm{RPMI}_{\text {modi }}$ and adenylate energy charges (b). Curves and columns are colored according to the antibiotic stresses: control (black), cefotaxime

For both methods, specimens were then dehydrated in graded series of ethanol (30-100\%) on ice for 30 min each step, and finally the material was stepwise infiltrated with the acrylic resin LR White according to Hammerschmidt et al. [35]. Sections were cut on an ultramicrotome (Reichert Ultracut, Leica UK Ltd, Milton Keynes, UK), stained with $4 \%$ aqueous uranyl acetate for $5 \mathrm{~min}$ and analyzed with a transmission electron microscope LEO 906 (Carl Zeiss Microscopy GmbH, Oberkochen, Germany). The micrographs were edited by using Adobe Photoshop CS6.

\section{Statistics and visualization}

Statistical analysis and visualization of data were carried out by using the Prism v7 software (GraphPad). The $p$ values were calculated based on two-way ANOVA and significance level of 0.05 was corrected for multiple testing by Šidák. Color-coded heat maps were created with $\mathrm{MeV}$ (v4.9). The changes in the extracellular metabolome were analyzed by fold change (FC) calculation of concentrations of each metabolite for each time point relative to the control at the corresponding time point and normalization to the optical density measured at the respective sampling time (see Table S3 in Supplementary material). For the intracellular metabolome there was a normalization step in the sampling protocol. Always 15 OD units of bacteria were sampled and divided into equal parts after extraction for analysis by HPLC-MS and GC-MS.

\section{Results}

\section{Inventory of pneumococcal metabolic profile}

To analyze the metabolic adaptation of $S$. pneumoniae TIGR $4 \Delta c p s$ to different antimicrobial compounds, bacterial cells were exposed to antibiotics during exponential growth b

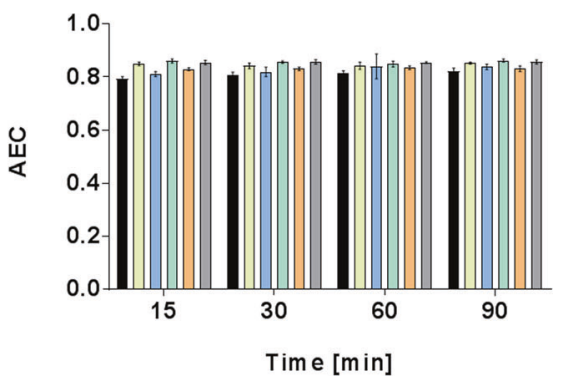

(yellow), azithromycin (blue), combination of cefotaxime and azithromycin (green), moxifloxacin (orange), and teixobactin-Arg10 (gray). Data are shown as mean values \pm standard derivation $(n=4-5)$

phase. The fast doubling time of the bacteria during this phase ensures a fast turnover of metabolites in the bacteria and thus excellent conditions to study the influence of certain antibiotics on the pneumococcal metabolome. Extraand intracellular metabolome samples were taken in a time span of $2 \mathrm{~h}$ (starting point OD of 0.5 ) to observe fast and time-resolved alterations. The largest growth difference between control and drug treatment was observed $90 \mathrm{~min}$ after adding the antimicrobial compounds (Fig. 1a). In addition to MIC determination (see Fig. S1 in Supplementary material), the CFU were counted (see Fig. S2 in Supplementary material). Furthermore, stressed and control bacteria were examined by transmission electron microscopy at $t_{90}$ after antimicrobial stress, to highlight which morphological variations may be linked to alterations within the metabolome (Fig. S3). The cell wall was only altered in cells stressed by moxifloxacin and teixobactin-Arg10 (Fig. S3). Bacterial cells treated with teixobactin-Arg10 presumably showed a defective cell wall and thus cell components escaped from the cells. In addition, all stressed cells with exception of cells treated with azithromycin showed more and longer white areas inside compared with control. In the control cells and cells stressed with azithromycin the areas were very weak.

The AEC was determined for each sample. In this study, the AEC was $0.84 \pm 0.02$ for pneumococcal cells under control and stress conditions (Fig. 1b).

Using ${ }^{1} \mathrm{H}$ NMR spectroscopy, HPLC-MS and GC-MS, 124 compounds were identified and analyzed (see Supplementary material Tables S3-S6) to cover a broad range of the chemically diverse metabolites. By using ${ }^{1} \mathrm{H}$ NMR, 37 metabolites were identified and quantified by using a library of standard spectra. Quantification of 90 metabolites by GCMS and HPLC-MS was verified by using labeled analytical standard compounds (see Supplementary Table S2). In summary, different metabolic pathways such as glycolysis, the pentose phosphate pathway, peptidoglycan biosynthesis, 
Table.1 Table showing numbers of intracellular metabolites significantly changed in amounts $(p \leq 0.05)$

\begin{tabular}{|c|c|c|c|c|c|c|c|c|c|c|}
\hline & \multicolumn{2}{|c|}{ Cefotaxime } & \multicolumn{2}{|c|}{ Azithromycin } & \multicolumn{2}{|c|}{$\begin{array}{l}\text { Cefotaxime + } \\
\text { azithromycin }\end{array}$} & \multicolumn{2}{|c|}{ Moxifloxacin } & \multicolumn{2}{|c|}{ Teixobactin-Arg10 } \\
\hline & Increased & Decreased & Increased & Decreased & Increased & Decreased & Increased & Decreased & Increased & Decreased \\
\hline Carbon metabolism & 9 & 5 & 2 & 3 & 13 & 4 & 6 & 4 & 8 & 4 \\
\hline Amino acid metabolism & 17 & 2 & 1 & 3 & 18 & 2 & 4 & 2 & 11 & 5 \\
\hline Nucleotide metabolism & 2 & 18 & 0 & 15 & 3 & 18 & 11 & 10 & 2 & 20 \\
\hline Cell wall precursors & 2 & 4 & 1 & 5 & 4 & 3 & 4 & 2 & 5 & 3 \\
\hline Other intermediates & 2 & 2 & 0 & 2 & 3 & 5 & 4 & 1 & 3 & 4 \\
\hline Total & 63 & & 32 & & 73 & & 48 & & 65 & \\
\hline
\end{tabular}
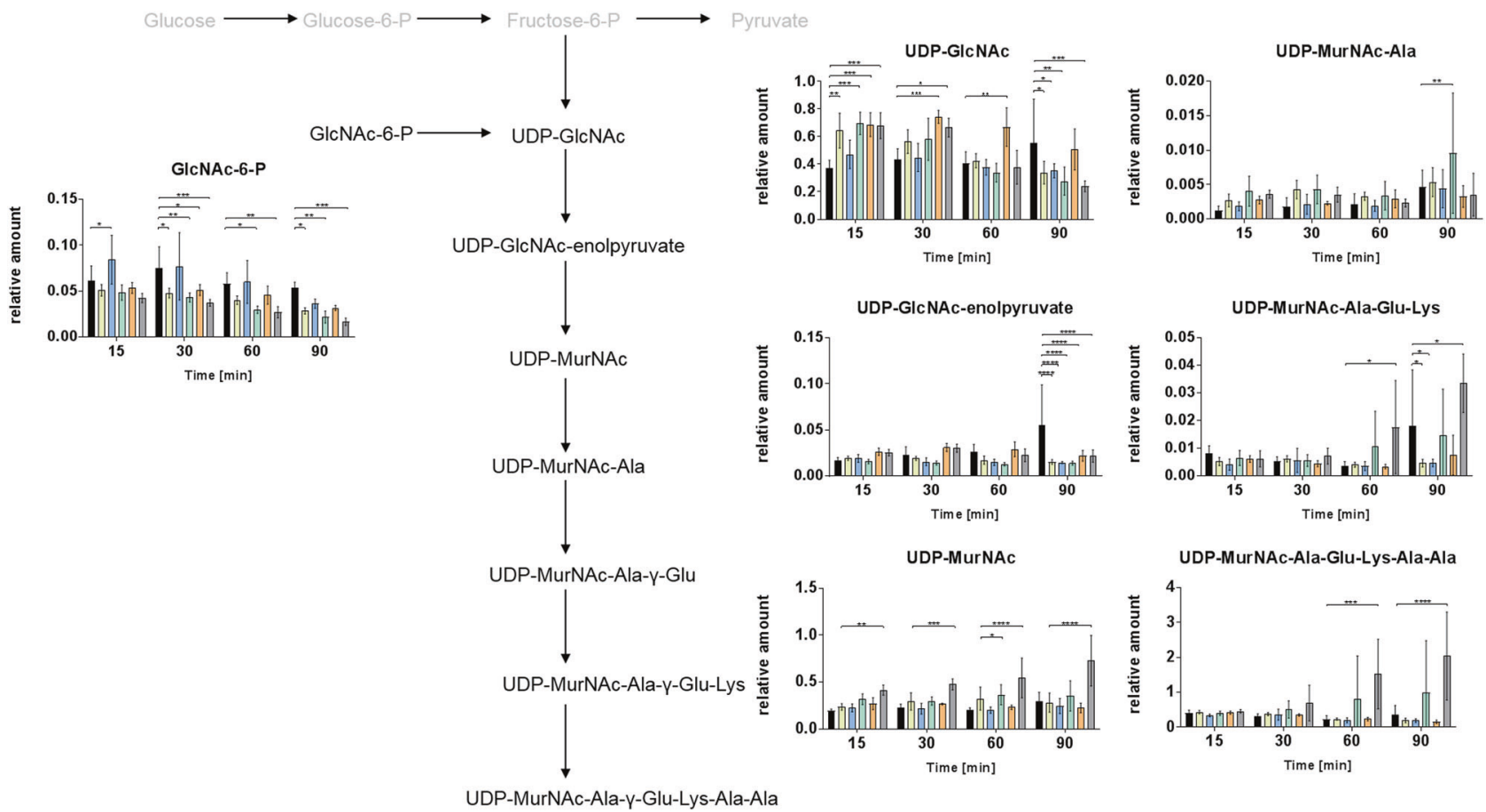

Fig. 2 Intermediates of peptidoglycan biosynthesis of $S$. pneumoniae TIGR4 4 cps. Relative amounts of intracellular metabolites are presented as bar charts. Columns $(n=4-5)$ are colored according to the antibiotic stresses: control (black), cefotaxime (yellow), azithromycin (blue), combination of cefotaxime and azithromycin (green),

purine and pyrimidine nucleotide metabolism, cofactor and amino acid metabolism were affected (Table 1). Two kinds of metabolic changes were observable: on the one hand time-dependent metabolic alterations and on the other hand antibiotic stress-dependent changes were visible.

\section{Cefotaxime treatment dependent metabolic alterations}

The treatment of pneumococci with cefotaxime changed significantly the levels of 63 intracellular metabolites compared with control conditions. Thereof, 32 metabolites were increased in amount (Table 1). Cefotaxime as inhibitor of moxifloxacin (orange), and teixobactin-Arg10 (gray). Asterisks indicate significant differences $(\alpha=0.05$ after Sidak correction) between the treated cells and the control. ${ }^{*} p \leq 0.05 ; * * p \leq 0.01 ; * * * p \leq 0.001$; $* * * * p \leq 0.0001$

cell wall synthesis caused significant decrease in amounts of cell wall precursors UDP-GlcNAc, GlcNAc-6-P, and UDPMurNAc-Ala-Glu-Lys at $t_{90}$ (Fig. 2). Surprisingly, strong effects of cefotaxime stress were found for glycolysis, amino acid, and nucleotide metabolism. The levels of all glycolytic metabolites following 1,3-bisphosphoglycerate (1,3-bP-glycerate) were enhanced compared with control at $\mathrm{t}_{15}$. Increase in amount of pyruvate was also more than twofold, but not significant $(p>0.05)$ (Fig. 3). The enhanced intracellular pyruvate concentration may cause the observed changes in the amount of associated metabolites as observed for alanine as well as acetyl-CoA and lactate (both $p>0.05$ ). The intracellular concentration of alanine was increased at $\mathrm{t}_{15}$ and 
a cefotaxime azithromycin $\mid$ combination $\mid$ moxifloxacin $\mid$ teixobactin-Arg10 \begin{tabular}{ll|l|l|l|l|l|l|l|l}
15306090 & 15306090 & 15306090 & 15306090 & 15306090
\end{tabular}
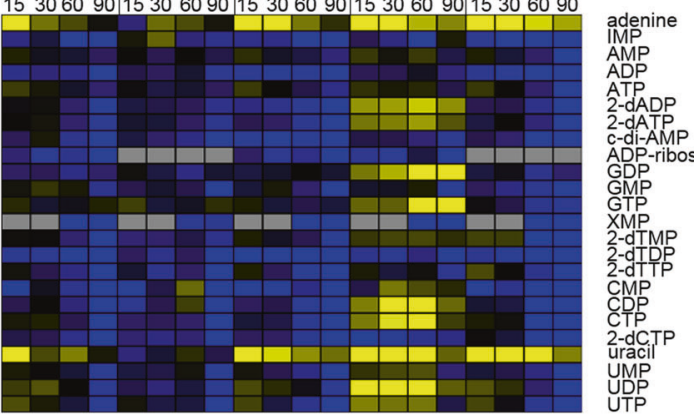

C cefotaxime |azithromycin combination |moxifloxacin teixobactin-Arg10 \begin{tabular}{ll|l|l|l|l|l|l|l|l}
15306090 & 15306090 & 15306090 & 15306090 & 15306090
\end{tabular}

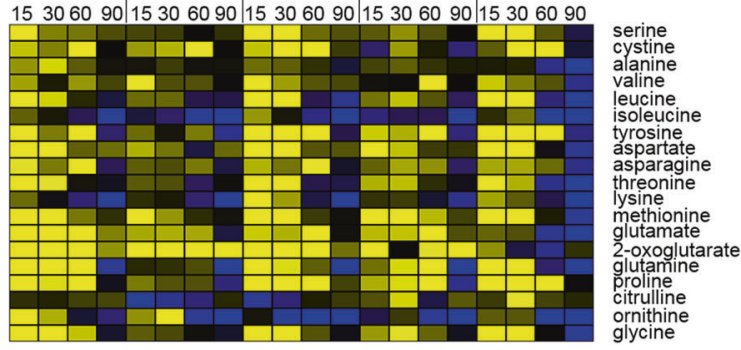

Fig. 3 Intracellular metabolites of (a) purine and pyrimidine metabolism, (b) carbon metabolism, and (c) amino acid metabolism of $S$. pneumoniae TIGR4 4 cps. The illustrated heat maps with fold changes (FC) of metabolite concentrations under conditions of antibiotic treatment referred to control shows metabolites with increased b cefotaxime azithromycin |combination moxifloxacin teixobactin-Arg10 \begin{tabular}{ll|l|l|l|l|l}
15306090 & 15306090 & 15306090 & 15306090 & 15306090
\end{tabular}

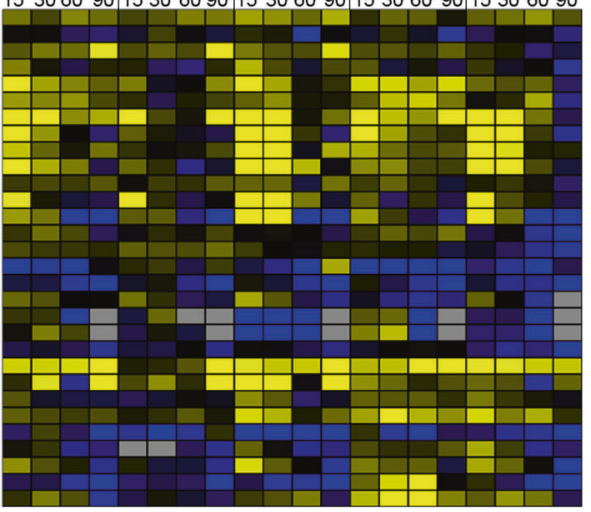

glucose-6-phosphate frucotse-6-phosphate 1,3-bisphosphoglycerate 3-phosphoglycerate 2-phosphoglycerate pyruvate phenylpyruvate dihydroxyacetone phosphate dihydroxyace malonyl-CoA sedoheptulose-1,7-bisphosphate sedoheptulose-7'-bisphosphate ribose-5-phosphate PRPP

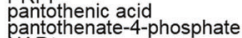
$\mathrm{NAD}^{+}$ NADP+ + -myo-inositol triphosphate glycerol -1-phosphate GSSG -1-phosph UDP-glucose
CDP-choline
CDP-ribitol

$$
F C=\frac{\text { mean value } t_{x}(\text { treatment })}{\text { mean value } t_{x}(\text { ctrl })}
$$

concentrations compared with unstressed bacteria in yellow and with decreased concentrations in blue at the different time points $\left(\mathrm{t}_{15}-\mathrm{t}_{90}\right)$. Gray fields: metabolites were not detected under stress and/or control conditions

antibiotics. In total, abundances of 32 metabolites were influenced significantly compared with untreated pneumococci. Although, four intracellular metabolites showed a significant increase and 28 metabolites a decrease in amount (Table 1). Pneumococci stressed with azithromycin showed no significant changes in amino acid metabolome with exception of altered levels of methionine, lysine, and isoleucine, which were influenced the same way by all other antibiotic treatments in this study. 2-Oxoglutarate as intermediate of glutamine/glutamate metabolism was increased two- to five-fold in amount intracellularly at all time points (Fig. 3). Also, glycolysis was less affected compared with other stress conditions. Glycolytic metabolites like fructose-1,6-bisphosphate (frc-1,6-bP) and phosphoenolpyruvate (PEP) showed enhanced concentrations $90 \mathrm{~min}$ after adding azithromycin ( $\left.t_{90}\right)$ (Fig. 3). Both, pyruvate as end product of glycolysis and the fermentation product lactate were found in similar amounts as in control samples.

The inhibitor of protein synthesis azithromycin decreased significantly the amounts of all detected intracellular purine and pyrimidine metabolites at $\mathrm{t}_{90}$ (XMP $(p>0.05)$ ) (Fig. 3). Only the purine nucleotides GDP, GTP, and IMP seems to be not affected after azithromycin stress. 


\section{Treatment with the combination of antibiotics- cefotaxime and azithromycin}

After pneumococcal exposure to cefotaxime and azithromycin, the intracellular abundances of 73 metabolites were significantly changed compared with control cells. These included 41 increased and 32 decreased metabolites. Bacterial treatment with the combination of the antibiotics induced the largest changes in the metabolome compared with other antimicrobial stress conditions. Surprisingly, seven metabolites showed significant changes only by treatment with combination of the two antibiotics azithromycin and cefotaxime and not by single usage: threonine $\left(t_{90}\right)$, 4-P-pantothenate $\left(t_{15}\right.$ and $\left.t_{30}\right)$, acetyl-CoA $\left(\mathrm{t}_{15}-\mathrm{t}_{60}\right)$, malonyl-CoA $\left(\mathrm{t}_{15}\right)$, glutathione disulfide (GSSG) $\left(\mathrm{t}_{15}\right)$, UDP-MurNAc $\left(\mathrm{t}_{60}\right)$, and UDP-MurNAc-Ala $\left(\mathrm{t}_{90}\right)$ (Figs. 2, 3). Also, UDP-MurNAc-Ala-Glu-Lys-Ala-Ala showed increased amount $(p>0.05)$ at $\mathrm{t}_{90}$, which is contrary to the alternations by treatment with cefotaxime only. Other noticeable effects of combination treatment were intensified glycolytic metabolic alterations compared with single usage. The amounts of 1,3-bP-glycerate and following metabolites of glycolysis until pyruvate were significantly increased, as well as amounts of phenylpyruvate, lactate, acetyl-CoA, and malonyl-CoA.

The changes in the intracellular amino acid metabolism caused by the treatment with cefotaxime were also found in the combination treatment with cefotaxime and azithromycin. Furthermore, all detected nucleotides with exception of GDP and GTP showed a decreased intracellular abundance, which was comparable to cefotaxime stress. Furthermore, similar effects were observed for adenine and uracil (Fig. 3).

In summary, cells stressed by combined treatment mostly showed metabolic changes similarly to cells stressed with cefotaxime (Fig. 3).

\section{DNA gyrase inhibitor moxifloxacin}

The fluoroquinolone moxifloxacin had a significant effect on the amounts of 48 metabolites. The abundances of 29 metabolites were increased and 19 metabolites were decreased.

Most alterations were found for the purine and pyrimidine nucleotide metabolism. Levels of adenine, AMP, 2dADP, 2-dATP, uracil, and the di- and triphosphates of uridine, cytidine, and guanosine were increased intracellularly. Reduced amounts of the other detected nucleotides were found after antibiotic treatment compared with control cells with exception of 2-dTMP, AMP, CMP, and UMP showing no changes (Fig. 3).

Intermediates of glycolysis such as 3-phosphoglycerate $\left(\mathrm{t}_{30}, \mathrm{t}_{60}\right.$, and $\left.\mathrm{t}_{90}\right), 2$-phosphoglycerate $\left(\mathrm{t}_{30}, \mathrm{t}_{60}\right)$, PEP $\left(\mathrm{t}_{90}\right)$, and pyruvate $\left(\mathrm{t}_{15}\right)$ were increased. Pneumococci treated with moxifloxacin showed alterations in several amino acids like leucine, proline, glycine, serine, threonine, aspartate, glutamate, tryptophan, and more $(p>0.05)$ (Fig. 3). Changes of concentration of cell wall metabolites were also detected (Fig. 2). The amount of UDP-GlcNAc was increased significantly at $\mathrm{t}_{15}-\mathrm{t}_{60}$ and UDP-GlcNAc-enolpyruvate $\left(\mathrm{t}_{90}\right)$ and GlcNAc-6-P $\left(\mathrm{t}_{30}\right)$ were decreased. We found that pneumococci stressed with moxifloxacin contained enhanced concentrations of three building blocks of teichoic acids namely glycerol-1-phosphate, CDP-ribitol (both $p<$ 0.05 at all time points), and CDP-choline ( $p>0.05)$ (Fig. 3). As specific as in the case of the building blocks for teichoic acids, abundance of 4-P-pantothenate was increased in the cells at $t_{15}$ and $t_{30}$ after stress induction.

\section{Teixobactin-Arg10 stress metabolic alterations}

The lipid II binder teixobactin-Arg 10 caused alterations in concentrations of 65 pneumococcal metabolites compared with control. Amounts of 29 metabolites were increased and 36 metabolites decreased significantly. Teixobactin-Arg 10 caused enrichment of cell wall precursors UDP-MurNAc, UDP-MurNAc-Ala-Glu-Lys, and UDP-MurNAc-Ala-GluLys-Ala-Ala and also influenced concentrations of other intermediates of peptidoglycan synthesis such as GlcNAc6P, UDP-GlcNAc, and UDP-GlcNAc-enolpyruvate (Fig. 2). Abundance of glycerol-1-phosphate was increased from $t_{15}$ to $t_{60}$ after stress induction.

The intracellular amounts of glycolysis intermediates and lactate were increased in pneumococci shortly after stress induction e.g., phosphoenolpyruvate $(p>0.05)$ and pyruvate at $t_{15}$ and $t_{30}$ after treatment and phenylpyruvate, as well as acetyl-CoA at $t_{15}$. However, 90 min after stress induction the level of pyruvate was decreased compared to control conditions (Fig. 3). Increased concentrations were also detected for pyruvate extracellularly (Fig. 4). Another effect of the teixobactin analog was observed in the changed arginine-ornithine antiporter regulation. Ornithine secretion stopped after treatment with teixobactin-Arg10, but uptake of arginine was unchanged compared to control and other stress conditions (Fig. S4). In summary, teixobactin-Arg 10 caused most metabolic changes in the exometabolome, for example observed for phenylalanine $\left(t_{15}\right.$ and $\left.t_{60}\right)$, tyrosine $\left(t_{15}\right)$, serine $\left(t_{15}\right)$, asparagine $\left(t_{15}\right)$. Levels of amino acids like glycine, serine, tyrosine, proline, aspartate and asparagine were increased intracellularly shortly after beginning of stress $\left(t_{15}-t_{30}\right)$. The same observations were made for glutamine and leucine $(p>0.05)$. Uptake or secretion of amino acids was not influenced. In contrast concentrations of most amino acids dropped down intracellularly under stress conditions compared to control at $\mathrm{t}_{90}(p>0.05)$ (Figs. 3, 4). 


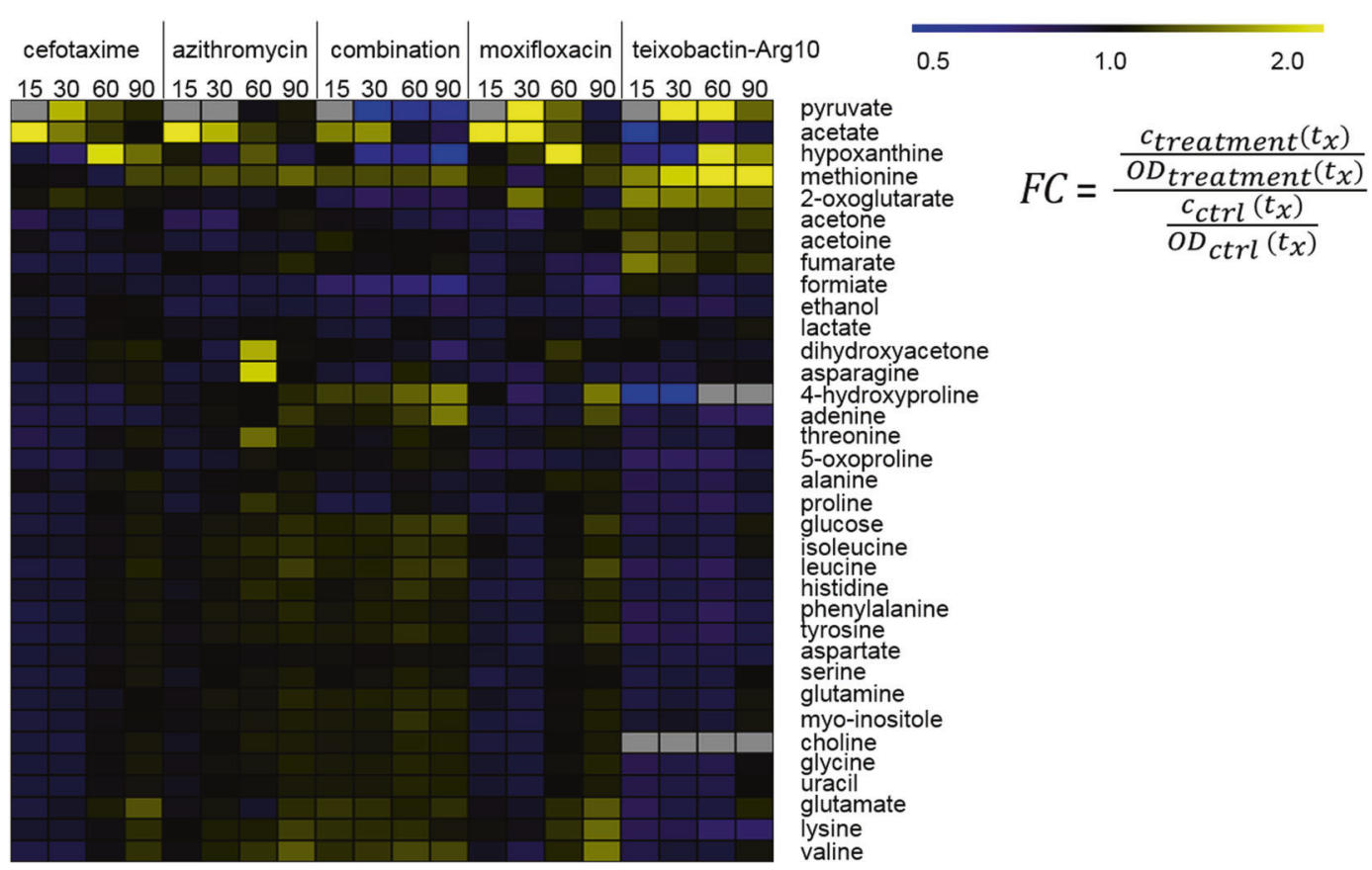

Fig. 4 Extracellular metabolites of $S$. pneumoniae TIGR4 4 cps. The illustrated heat map with fold changes (FC) of metabolite amounts after addition of antibiotics referred to control conditions both with normalization to optical density $(600 \mathrm{~nm})$ shows metabolites with higher concentrations compared to control in yellow and with lower concentrations in blue at the different time points $\left(\mathrm{t}_{15}-\mathrm{t}_{90}\right)$. Gray fields: metabolites were not detected under stress and/or control conditions
Among the 36 metabolites with decreased amounts were many purine and pyrimidine metabolites, for instance all detected nucleotides and deoxy nucleotides showed lower concentrations at $t_{60}$ and $t_{90}$ after teixobactin-Arg10 stress when compared to the control. Also, lower abundance was found for 6-phosho gluconate. Only adenine $(p<0.05$ for all time points) and uracil $\left(p<0.05\right.$ for $\left.t_{15}-t_{60}\right)$ level were increased intracellularly compared to control conditions (Fig. 3).

\section{General stress-dependent metabolic changes}

The amounts of amino acids and cell wall precursors as well as nucleotides were altered in pneumococci by all stress conditions. The intracellular methionine amount was increased at $t_{15}$ and $t_{30}$. In contrast, other amino acid concentrations were reduced at $t_{90}$ e.g., concentrations of lysine, isoleucine (both $p<0.05$ ), glutamine and ornithine (both $p>0.05$ ). The amounts of the nucleotides ADP, ADP-ribose, ATP, c-di-AMP, GMP, UMP, 2-dCTP, 2dTDP and 2-dTTP decreased intracellularly during all stress conditions at $t_{90}$ (Fig. 3). Furthermore, levels of ribose-5-P, malonyl-CoA and UDP-GlcNAc-enolpyruvate decreased intracellularly at $t_{90}$ (Figs. 2, 3). A general increase in concentration was only observed for $\mathrm{NADP}^{+}$ at all time points with exception of treatment with azithromycin causing only increase in $\mathrm{NADP}^{+}$level at $\mathrm{t}_{90}$ (Fig. 3).

\section{Discussion}

The traditional therapies for pneumococcal-induced pneumonia include $\beta$-lactam, macrolide, fluoroquinolone and tetracycline antibiotics [36]. Resistance to penicillin and macrolide antibiotics in $S$. pneumoniae has increased in many areas [37]. Small molecules like antibiotics can have pleiotropic effects on bacteria, which was demonstrated in our study. Our investigations were focused on the nonencapsulated strain $S$. pneumoniae TIGR4 4 cps. Specific differences in metabolism of $S$. pneumoniae strains have to be considered for a generalization of our results. We used antimicrobial compounds with classical and novel targets towards the bacterial metabolism at a single concentration to cover a broad range of responses in metabolic pathways. Including this study, several OMICs studies have been performed to demonstrate the effect of antibiotics on pneumococcal physiology [38-45].

\section{Impact of antibiotics as general metabolic changes}

The AEC as ratio of ATP, ADP, and AMP describes the energy balance of cells. In living cells, the AEC is near 0.85 , if the formation of ATP is controlled primarily by the concentration of the regulatory end product [46]. Chapman et al. showed that depletion of the carbon source glucose caused a decreased AEC in Escherichia coli [47]. In this study, during the whole experiment pneumococci had no 
limitation of glucose. At $t_{90}$ after antibiotic treatment, about $22 \mathrm{mM}$ glucose was available for the bacteria. The antibiotic treatment caused reduced levels of adenosine nucleotides but not affected the resulting AEC, so energy balance of the bacteria seems not to be influenced.

General, the effect of enhanced amino acid levels is described to be a stress response of $S$. pneumoniae to antibiotics [10, 48]. Bacterial stress mechanisms induce an increased synthesis of amino acids, which are precursors for protection proteins like CodY [49]. Methionine is essential for growth of pneumococcal cells $[10,50]$ and intracellular methionine concentration was increased immediately after initiation of stress conditions. Methionine is involved in many anabolic reactions like protein biosynthesis, $N$-formylmethionine formation and $S$-adenosylmethionine synthesis. Studies showed that a mutation of the MetQNP ABCtransporter and the methionine synthetase metQ/metEF induced an inhibition of pneumococcal growth [50, 51]. $S$. pneumoniae might show an adaptation in the metabolism in raising the level of methionine to protect the cells.

The intracellular level of c-di-AMP significantly decreased in all stressed cells at $t_{90}$ after addition of antibiotics. For Staphylococcus aureus a very low level of c-diAMP is supposed to contribute to reduced bacterial growth rate [52]. Cell wall biosynthesis seems to be affected not only by specific inhibitors like cefotaxime because diverse effects on synthesis of cell wall precursors were observed for all antibiotics. However, all stress conditions led to significant reduction in levels of the cell wall precursor UDP-GlcNAc-enolpyruvate. This might be connected with a general influence of antibiotic treatment on glutamine metabolism of S. pneumoniae resulting in decreased level of glutamine and Glc-NAc-6-P at $t_{90}$.

Another general effect seems to be a downregulation of PPP providing reduction equivalents by reducing $\mathrm{NADP}^{+}$. $\mathrm{NADP}^{+}$was detected in increased amounts and ribose-5phosphate, as another important product of PPP, in decreased amounts after all stress conditions. Lower level of ribose-5-phosphate as precursor of nucleotide biosynthesis might be connected with dropping of nucleotide amounts at $t_{90}$. Increased amounts of $\mathrm{NADP}^{+}$were shown in S. aureus among different antibiotic treatments only with fluoroquinolone ciprofloxacin [53].

\section{Impact of cephalosporin cefotaxime on the metabolism of S. pneumoniae}

Metabolic response of S. pneumoniae to cefotaxime showed an increased amount of glutamine and glutamate intracellularly. Glutamine is major nitrogen donor for purine and pyrimidine biosynthesis and for the synthesis of the cell wall precursors. Glutamine is used by the aminotransferase GlmS to convert fructose-6-P into glucosamine-6-P [54, 55]. As shown in $S$. aureus inhibition of GlmS correlates with a broad set of cell wall synthesis inhibitors [56]. Transcriptional response of $S$. pneumoniae to penicillin showed decreased glutamine metabolism. The most downregulated genes encode ABC transporter $\mathrm{GlnQ}$, the transcriptional regulator $\mathrm{GlnR}$, and the glutamine synthetase GlnA [38]. Enhanced intracellular concentrations of glutamine and glutamate as described for $S$. pneumoniae after penicillin treatment [38] were also observed after exposure to cefotaxime in this study whereas uptake of glutamine and glutamate was not influenced. Interestingly, it was shown that glutamine protects $S$. pneumoniae against penicillin stress [38]. The inhibition of GlmS in methicillinresistant $S$. aureus [56] and of GlnA in penicillin-resistant $S$. pneumoniae [38] decreased their level of resistance. Glutamine is also a cofactor for the cross-linking of the peptidoglycan by MurT/GatD [57]. Our results showed that cefotaxime influenced the amounts of four peptidoglycan precursors reaffirming the known mechanism of action of cephalosporins [58].

Increased amounts of threonine were detected in pneumococcal stress response. Threonine is part of the active site of penicillin binding protein $2 \times(\mathrm{PBP} 2 \mathrm{x})$. After binding of cefotaxime to $\mathrm{PBP} 2 \mathrm{x}$, threonine has directly contact with the cephalosporin [59]. Loss of the hydrogen bond between cefotaxime and threonine is known to induce resistance [60]. Thus, threonine could be a crucial metabolite in formation of resistance. In this study, cefotaxime stress increased the amount of threonine intracellularly.

The results of the metabolome analysis revealed variations of peptidoglycan biosynthesis. Therefore, the pneumococcal cell morphology was investigated and visualized. The cell wall was not affected in thickness or morphology. Conspicuously were the white areas in the TEM images. Hoyer et al. could show similar effects depending on medium composition that also strongly influenced the protein expression in S. pneumoniae [61]. The areas in the TEM images could be granular of a storage substance that was not detectable by metabolome analysis. Poly- $\beta$ hydroxybutyrate (PHB) is an intracellular storage material found in Lactobacillus, Lactococcus, Pediococcus, and Streptococcus species. The bacteria accumulate PHB during the stationary phase of growth [62]. However, for $S$. pneumoniae PHB is hitherto unknown.

\section{Impact of macrolide azithromycin on the metabolism of S. pneumoniae}

Macrolides have shown some strong anti-inflammatory effects [63], reducing the release of IL- 8 and TNF- $\alpha$. Also macrolides inhibit effective adherence of bacteria to respiratory epithelial cells and so decrease the production of virulence factors [64]. It has been demonstrated that azithromycin blocks peptide biosynthesis resulting in a reduced uptake of amino acids from the medium [53]. Our 
findings showed no significant changes of amino acid uptake and intracellular concentrations by azithromycin stress. Interestingly, macrolides can be secreted by ATP dependent efflux pumps from pneumococcal cells $[65,66]$. A study using $E$. coli has suggested a physical interaction between macrolide efflux proteins $\operatorname{Mef}(\mathrm{E})$ and Mel, binding of macrolides to Mel and localization to the membrane [67]. Induction of efflux proteins occurs very fast after exposure to different macrolide antibiotics [68]. Efflux of antibiotics could be a reason that $S$. pneumoniae showed least metabolic alteration caused by azithromycin compared with other stress conditions. In this study, azithromycin treatment of $S$. pneumoniae influenced the purine and pyrimidine biosynthesis as also proved for S. aureus [53, 69]. These results suggested that the bacterial cells responded to azithromycin by reducing generation of nucleotides and resources for DNA synthesis [69].

\section{Impact of combination of cefotaxime and azithromycin on the metabolism of $S$. pneumoniae}

A drug combination therapy is increasingly used in the hospitals because of better coverage in polymicrobial CAP. It has been suggested that $S$. pneumoniae-induced pneumonia patients have concomitant Mycoplasma pneumoniae or Legionella sp. infections [6, 63]. Combination therapy acts at two different sites in bacteria i.e., the inhibition of cell wall biosynthesis by $\beta$-lactams, and inhibition of protein synthesis by macrolides. Our study showed for the first time metabolome adaptations of $S$. pneumoniae to combined stress of cefotaxime and azithromycin. Combined application of these two antibiotics resulted in a largest change in the metabolome of $S$. pneumoniae compared to the other antimicrobial treatments. Comparable metabolic changes were observed when cefotaxime was applied solely, e.g., on amino acid metabolism. But combination treatment seemed to intensify the effects on glycolysis and lactate formation as well as nucleotide biosynthesis compared to cefotaxime alone. However, there were also significant changes of seven metabolites only caused by the combined treatment with cefotaxime and azithromycin. Probably these additional effects on the pneumococcal metabolism could be a reason for better outcome of CAP patients. Glutathione is used as a marker of oxidative stress [70]. Only after treatment with cefotaxime and azithromycin an altered level of oxidized glutathione (GSSG) was found.

\section{Impact of fluoroquinolone moxifloxacin on the metabolism of S. pneumoniae}

The treatment of $S$. pneumoniae with moxifloxacin causes double-stranded breaks in the bacterial chromosome [42] and requires active protein synthesis [71]. Treatment with moxifloxacin was reported not altering the level of global supercoiling [42]. Moxifloxacin induces transcriptional changes, which ultimately stimulate the Fenton reaction, increasing ROS accumulation and contributing to cell death [42]. S. pneumoniae treated with the fluoroquinolone induces upregulation of the $f a t D C E B$ operon coding an iron transporter. Subsequently, the intracellular iron concentration increased leading to accumulation of ROS [72]. De la Campa et al. reviewed that for the facultative anaerobic bacterium, S. pneumoniae, the increased lethality of fluoroquinolones is mediated by an increase in ROS fiting with the antibiotic lethality model proposed for aerobic bacteria [40].

The transcriptomic response of $S$. pneumoniae R6 to moxifloxacin led to an upregulation of metabolic pathways involved in the production of pyruvate [42]. Similar to Ferrandiz et al. which showed an increase in acetyl-CoA [42], our study demonstrated also increased abundances of glycolytic intermediates and pyruvate. Interestingly, acetylCoA showed no altered level compared to the control in this study but increase in amount of acetate extracellularly. The inhibition of DNA and RNA synthesis led to a block in septum formation and a more thickened cell wall [73]. Morphological changes of cell wall could be confirmed in our study. In S. aureus, a downregulation of metabolism on transcriptomic level was found by treatment with the fluoroquinolone ciprofloxacin, including purine and pyrimidine biosynthesis [69]. Furthermore, in S. aureus an increase of nucleotides and nucleosides was detected [53]. Also genes of purine and pyrimidine biosynthesis were upregulated in S. pneumoniae R6 treated with moxifloxacin [42]. Both fits well with our results, nearly half of all detected nucleotides were increased in amounts significantly in S. pneumoniae cells under moxifloxacin stress. Changed levels of cell wall intermediates as observed for Streptococcus faecalis [73] were also detected in our study. CDP-ribitol was significantly influenced only by moxifloxacin treatment, so it could function as a marker of moxifloxacin stress in our study. Increased amounts of CTP might be connected with the enhanced level of CDP-ribitol. Further investigations of $S$. pneumoniae on metabolome level are necessary including all other antibiotic drug classes to confirm this metabolite as marker.

\section{Impact of Arg10 teixobactin on the metabolism of $S$. pneumoniae}

The need for new antibiotics for treatment of resistant pathogens become a major global concern for human health. The isolation of teixobactin in 2015 by Ling et al. raised great expectations [74]. It was one of a few novel antibiotics that have been reported in recent years showing no resistance development [28]. The naturally occurring molecule, 
teixobactin, has the same limitations due to the low yield [29]. Pamar et al. designed and synthesized potent teixobactin analogs [31, 75]. This was the first study that investigated the effects of a teixobactin analog on bacterial metabolism by using teixobactin-Arg10. Lipid II as one of the known targets of teixobactin is removed from the cytoplasmic membrane prior to incorporation of its disaccharide-peptide moiety into peptidoglycan [76]. The binding of teixobactin prevents the removal of lipid II. The pyrophosphate group and the attached first sugar subunits of lipid II was found to be a minimal motif for stabile teixobactin binding [77]. In our study, we observed an accumulation of the three peptidoglycan precursors UDPMurNAc, UDP-MurNAc-Ala, and UDP-MurNAc-Ala-GluLys-Ala-Ala confirming the inhibition of peptidoglycan synthesis in S. pneumoniae treated with teixobactin-Arg10. Formation of excrescence found in transmission electron micrographs of S. pneumoniae TIGR4 4 cps cells pointed out changes in cell wall morphology. Teixobactin has an effect on cell morphology and destroyed cell wall integrity in S. aureus [78]. Our observations confirmed these results for S. pneumoniae TIGR $4 \Delta$ cps treated with the teixobaction analog.

The main metabolic pathway of $S$. pneumoniae is glycolysis [48]. Therefore, influences on glycolysis should be significant and changes are expected in metabolome. It is possible that increase of glycolysis intermediates indicates a stress response in this study. However, 90 min after antimicrobial stress, glycolysis metabolites are present in a decreased concentration compared with unstressed cells. Possibly the metabolism is downregulated by stress and consequently less energy is available.

Another interesting outcome was that the extracellular level of ornithine was influenced by the stress induced by teixobactin-Arg10. Arginine-ornithine antiporter (ArcD) is essential for the virulence of $S$. pneumoniae TIGR4 [79]. Arginine is one of the amino acids that cannot be synthesized de novo and has to be taken up by pneumococcus $[9,48]$. Uptake of arginine was unaffected but ornithine secretion was completely stopped by treatment with the teixobactin analog. Gupta et al. assumed another function for ArcD that affects the linkage of the capsular polysaccharide to pneumococcal cell wall [80], however, this aspect is not relevant for the non-encapsulated S. pneumoniae TIGR $4 \Delta$ cps. The deletion of $\operatorname{arcD}$ reduces the amount of capsule materials on the bacterial surface. ArcD appears to play different roles in the pathogenicity of various pneumococcal serotypes, as the deficiency of $\mathrm{ArcD}$ in another strain does not affect the capsule [80, 81].

Pyrimidine nucleotides play an important role in the biosynthesis of activated nucleotide sugars (NDP-sugars). NDP-sugars are precursors for the synthesis of exopolysaccharides and peptidoglycan in lactic acid bacteria [82].
Carvalho et al. proposed a link between pyrimidine metabolism and capsule biosynthesis in S. pneumoniae D39 $[83,84]$. Also they showed that uracil affects the pneumococcal capsule [85]. In our study, uracil concentration intracellularly increased after antibiotic stresses (teixobactin-Arg 10, moxifloxacin, cefotaxime, and combination of cefotaxime and azithromycin) and adenine concentration showed same changes. Cultivation medium was supplemented with both nucleobases, but uptake was not enhanced compared with control. Due to the use of non-encapsulated S. pneumoniae TIGR4, in our study uracil was not associated with capsule formation. High amounts of nucleobases and decreased level of nucleotides might refer to intensified degradation of nucleotides or inhibition of salvage pathways of nucleotide formation as an outcome of reduced growth.

\section{Conclusion and outlook}

The presented study showed intra- and extracellular metabolic changes of $S$. pneumoniae TIGR4 $\Delta$ cps stressed by different antimicrobial compounds. Possibly there are limitations in this approach resulting from the usage of only a single strain of $S$. pneumoniae and antibiotic concentration. Based on our findings, future investigations on metabolic adaptions of S. pneumoniae to antibiotic treatment should include different $S$. pneumoniae strains to exclude strainspecific reactions. The use of resistant bacteria utilizing resistance to a specific antimicrobial compound or compound class may allow to verify metabolic alterations to antibiotic stress in nonresistant strains. Furthermore, challenging bacteria with different concentrations of antibiotics could be helpful to study dose-dependent changes in metabolism.

No antibiotic showed a single alteration of a specific metabolite or a specific metabolic pathway in pneumococcal cells but rather a globally affected metabolome. Distinctive pathways affected were the purine and pyrimidine metabolism and the peptidoglycan biosynthesis as well. The fluoroquinolone moxifloxacin altered the nucleotide metabolism and teichoic acid precursors in a specific way. Typical for treatment with cefotaxime were enhanced levels of glutamine and glutamate and altered peptidoglycan metabolism. The fewest changes in the metabolome were caused by treatment with azithromycin, only remarkable changes in nucleotide metabolism were observed. A combination of cefotaxime and azithromycin resulted in metabolic variations mostly comparable to the application of cefotaxime alone. The teixobactin-Arg10 influenced level of peptidoglycan precursors as well as nucleotides and the arginine-ornithine antiporter. Given the broader global effects of the synthetic teixobactin analog on 
the metabolome of pneumococcal cells, it potentially provides a starting point for a new antibiotic treatment strategy.

Acknowledgements This work was supported by the Deutsche Forschungsgemeinschaft (DFG) DFG-GRK 1870 and Ministry of Education and Science (BMBF) Project "PyrBac" (FKZ 16GW0190). This research was further funded by the Mecklenburg-Pomerania Excellence Initiative (Germany) and European Social Fund (ESF) Grant KoInfekt (ESF_14-BM-A55-0005_16). We thank Prof. Sven Hammerschmidt for sharing the pneumococcal strain and for critical reading this study. We are grateful to Tanja Wilk, Daniel Schultz, and Martina Wurster for helpful discussions and support in the laboratory. We would like thank Annette Meuche for excellent technical assistance and Ishwar Singh for the provision of the Arg10 teixobactin analog.

Funding Open access funding provided by Projekt DEAL.

\section{Compliance with ethical standards}

Conflict of interest The authors declare that they have no conflict of interest.

Publisher's note Springer Nature remains neutral with regard to jurisdictional claims in published maps and institutional affiliations.

Open Access This article is licensed under a Creative Commons Attribution 4.0 International License, which permits use, sharing, adaptation, distribution and reproduction in any medium or format, as long as you give appropriate credit to the original author(s) and the source, provide a link to the Creative Commons license, and indicate if changes were made. The images or other third party material in this article are included in the article's Creative Commons license, unless indicated otherwise in a credit line to the material. If material is not included in the article's Creative Commons license and your intended use is not permitted by statutory regulation or exceeds the permitted use, you will need to obtain permission directly from the copyright holder. To view a copy of this license, visit http://creativecommons. org/licenses/by/4.0/.

\section{References}

1. File TM, Marrie TJ. Burden of community-acquired pneumonia in North American adults. Postgrad Med. 2010;122:130-41. https:// doi.org/10.3810/pgm.2010.03.2130.

2. O'Brien KL, et al. Burden of disease caused by Streptococcus pneumoniae in children younger than 5 years. Global estimates. Lancet. 2009;374:893-902. https://doi.org/10.1016/S0140-6736 (09)61204-6.

3. Mandell LA, et al. Infectious Diseases Society of America/ American Thoracic Society consensus guidelines on the management of community-acquired pneumonia in adults. Clin Infect Dis. 2007;44(Suppl 2):S27-72. https://doi.org/10.1086/511159.

4. World Health Organization. Pneumoniae. Fact sheet $\mathrm{N}^{\circ} 331$, Updated November 2015. http://www.who.int/mediacentre/fa ctsheets/fs331/en/.

5. van der Poll T, Opal SM. Pathogenesis, treatment, and prevention of pneumococcal pneumonia. Lancet. 2009;374:1543-56. https:// doi.org/10.1016/S0140-6736(09)61114-4.

6. García Vázquez E, et al. Lower mortality among patients with community-acquired pneumonia treated with a macrolide plus a beta-lactam agent versus a beta-lactam agent alone. Eur J Clin
Microbiol Infect Dis. 2005;24:190-5. https://doi.org/10.1007/ s10096-005-1295-9.

7. Berkley JA, et al. Bacteremia among children admitted to a rural hospital in Kenya. N Engl J Med. 2005;352:39-47. https://doi.org/ 10.1056/NEJMoa040275.

8. Bogaert D, de Groot R, Hermans PWM. Streptococcus pneumoniae colonisation: the key to pneumococcal disease. Lancet Infect Dis. 2004;4:144-54. https://doi.org/10.1016/S1473-3099(04) 00938-7.

9. Leonard, A et al. Metabolic inventory of Streptococcus pneumoniae growing in a chemical defined environment. Int $\mathrm{J}$ Med Microbiol. 2018. https://doi.org/10.1016/j.ijmm.2018.01.001.

10. Härtel $\mathrm{T}$, et al. Impact of glutamine transporters on pneumococcal fitness under infection-related conditions. Infect Immun. 2011;79:44-58. https://doi.org/10.1128/IAI.00855-10.

11. Hoskins J, et al. Genome of the bacterium Streptococcus pneumoniae strain R6. J Bacteriol. 2001;183:5709-17. https://doi.org/ 10.1128/JB.183.19.5709-5717.2001.

12. Lynch JP, Zhanel GG. Streptococcus pneumoniae. Epidemiology, risk factors, and strategies for prevention. Semin Respir Crit Care Med. 2009;30:189-209. https://doi.org/10.1055/s-0029-1202938.

13. Waterer GW, Somes GW, Wunderink RG. Monotherapy may be suboptimal for severe bacteremic pneumococcal pneumonia. Arch Intern Med. 2001;161:1837-42.

14. Weiss $\mathrm{K}$, et al. Clinical characteristics at initial presentation and impact of dual therapy on the outcome of bacteremic Streptococcus pneumoniae pneumonia in adults. Can Respir J. 2004;11:589-93. https://doi.org/10.1155/2004/461392.

15. Martínez JA, et al. Addition of a macrolide to a beta-lactam-based empirical antibiotic regimen is associated with lower in-hospital mortality for patients with bacteremic pneumococcal pneumonia. Clin Infect Dis. 2003;36:389-95. https://doi.org/10.1086/367541.

16. Waterer GW, Rello J. Choosing the right combination therapy in severe community-acquired pneumonia. Crit Care. 2006;10:115. https://doi.org/10.1186/cc3976.

17. Ginsburg AS, Grosset JH, Bishai WR. Fluoroquinolones, tuberculosis, and resistance. Lancet Infect Dis. 2003;3:432-42.

18. Caeiro J-P, Iannini PB. Moxifloxacin (Avelox). A novel fluoroquinolone with a broad spectrum of activity. Exp Rev Anti-infect Ther. 2003;1:363-70.

19. Hakenbeck R, Ellerbrok H, Briese T, Handwerger S, Tomasz A. Penicillin-binding proteins of penicillin-susceptible and -resistant pneumococci. Immunological relatedness of altered proteins and changes in peptides carrying the beta-lactam binding site. Antimicrob Agents Chemother. 1986;30:553-8.

20. Lee CE, et al. The incidence of antimicrobial allergies in hospitalized patients. Implications regarding prescribing patterns and emerging bacterial resistance. Arch Intern Med. 2000;160: 2819-22.

21. Carmine AA, Brogden RN, Heel RC, Speight TM, Avery GS. Cefotaxime. A review of its antibacterial activity, pharmacological properties and therapeutic use. Drugs. 1983;25:223-89. https:// doi.org/10.2165/00003495-198325030-00001.

22. Langtry HD, Balfour JA. Azithromycin. A review of its use in paediatric infectious diseases. Drugs. 1998;56:273-97. https://doi. org/10.2165/00003495-199856020-00014.

23. Bailly S, Pocidalo JJ, Fay M, Gougerot-Pocidalo MA. Differential modulation of cytokine production by macrolides. Interleukin- 6 production is increased by spiramycin and erythromycin. Antimicrob Agents Chemother. 1991;35:2016-9.

24. Dudas V, Hopefl A, Jacobs R, Guglielmo BJ. Antimicrobial selection for hospitalized patients with presumed communityacquired pneumonia. A survey of nonteaching US community hospitals. Ann Pharmacother. 2000;34:446-52. https://doi.org/10. 1345/aph.19174. 
25. Caballero J, Rello J. Combination antibiotic therapy for community-acquired pneumonia. Ann Intensive Care. 2011;1:48. https://doi.org/10.1186/2110-5820-1-48.

26. Blair JMA, Webber MA, Baylay AJ, Ogbolu DO, Piddock LJV. Molecular mechanisms of antibiotic resistance. Nat Rev Microbiol. 2015;13:42-51. https://doi.org/10.1038/nrmicro3380.

27. Clatworthy AE, Pierson E, Hung DT. Targeting virulence. A new paradigm for antimicrobial therapy. Nat Chem Biol. 2007;3:541-8. https://doi.org/10.1038/nchembio.2007.24.

28. Ling LL, et al. A new antibiotic kills pathogens without detectable resistance. Nature. 2015;517:455-9. https://doi.org/10.1038/na ture14098.

29. Parmar A, et al. Design and syntheses of highly potent teixobactin analogues against Staphylococcus aureus, Methicillin-Resistant Staphylococcus aureus (MRSA), and Vancomycin-Resistant Enterococci (VRE) in vitro and in vivo. J Med Chem. 2018;61:2009-17. https://doi.org/10.1021/acs.jmedchem.7b01634.

30. Leonard A, Lalk M. Infection and metabolism-Streptococcus pneumoniae metabolism facing the host environment. Cytokine. 2018;112:75-86. https://doi.org/10.1016/j.cyto.2018.07.021.

31. Parmar A, et al. Syntheses of potent teixobactin analogues against methicillin-resistant Staphylococcus aureus (MRSA) through the replacement of 1-allo-enduracididine with its isosteres. Chem Commun. 2017;53:7788-91. https://doi.org/10.1039/c7cc04021k.

32. Singh I, Taylor E. New antibacterial products. 2018. https://pa tentscope.wipo.int/search/en/detail.jsf?docId=WO2018162922\&ta $\mathrm{b}=$ PCTBIBLIO.

33. Heifets L. MIC as a quantitative measurement of the susceptibility of Mycobacterium avium strains to seven antituberculosis drugs. Antimicrob Agents Chemother. 1988;32:1131-6.

34. Atkinson DE. The energy charge of the adenylate pool as a regulatory parameter. Interact with feedback modifiers. Biochemistry. 1968;7:4030-4.

35. Hammerschmidt $\mathrm{S}$, et al. Illustration of pneumococcal polysaccharide capsule during adherence and invasion of epithelial cells. Infect Immun. 2005;73:4653-67. https://doi.org/10.1128/ IAI.73.8.4653-4667.2005.

36. Ewig S, et al. Behandlung von erwachsenen Patienten mit ambulant erworbener Pneumonie und Prävention-Update 2016. Pneumologie. 2016;70:151-200. https://doi.org/10.1055/s-0042101873.

37. European Antimicrobial Resistance Surveillance Network. Surveillance of antimicrobial resistance in Europe 2017. 2018.

38. El Khoury JY, Boucher N, Bergeron MG, Leprohon P, Ouellette M. Penicillin induces alterations in glutamine metabolism in Streptococcus pneumoniae. Sci Rep. 2017;7:14587. https://doi. org/10.1038/s41598-017-15035-y.

39. Fani F, Brotherton M-C, Leprohon P, Ouellette M. Genomic analysis and reconstruction of cefotaxime resistance in Streptococcus pneumoniae. J Antimicrob Chemother. 2013;68:1718-27. https://doi.org/10.1093/jac/dkt113.

40. La Campa AG, de, Ferrándiz MJ, Martín-Galiano AJ, García MT, Tirado-Vélez JM. The transcriptome of Streptococcus pneumoniae induced by local and global changes in supercoiling. Front Microbiol. 2017;8:1447. https://doi.org/10.3389/fmicb.2017. 01447.

41. Marrer E, Satoh AT, Johnson MM, Piddock LJV, Page MGP. Global transcriptome analysis of the responses of a fluoroquinolone-resistant Streptococcus pneumoniae mutant and its parent to ciprofloxacin. Antimicrob Agents Chemother. 2006;50:269-78. https://doi.org/10.1128/AAC.50.1.269-278. 2006.

42. Ferrándiz MJ, Martín-Galiano AJ, Arnanz C, Zimmerman T, La Campa AGde. Reactive oxygen species contribute to the bactericidal effects of the fluoroquinolone moxifloxacin in
Streptococcus pneumoniae. Antimicrob Agents Chemother. 2016;60:409-17. https://doi.org/10.1128/AAC.02299-15.

43. Chandra Mohana N, et al. Omics based approach for biodiscovery of microbial natural products in antibiotic resistance era. J Genet Eng Biotechnol. 2018;16:1-8. https://doi.org/10.1016/j.jgeb.2018. 01.006.

44. Rogers PD, et al. Gene expression profiling of the response of Streptococcus pneumoniae to penicillin. J Antimicrob Chemother. 2007;59:616-26. https://doi.org/10.1093/jac/dk1560.

45. Ng W-L, Kazmierczak KM, Robertson GT, Gilmour R, Winkler ME. Transcriptional regulation and signature patterns revealed by microarray analyses of Streptococcus pneumoniae R6 challenged with sublethal concentrations of translation inhibitors. J Bacteriol. 2003;185:359-70. https://doi.org/10.1128/JB.185.1. 359-370.2003.

46. Atkinson DE. Energy charge of the adenylate pool as a regulatory parameter. Interaction with feedback modifiers. Biochemistry. 1968;7:4030-4. https://doi.org/10.1021/bi00851a033.

47. Chapman AG, Fall L, Atkinson DE. Adenylate energy charge in Escherichia coli during growth and starvation. J Bacteriol. 1971;108:1072-86.

48. Härtel T, et al. Characterization of central carbon metabolism of Streptococcus pneumoniae by isotopologue profiling. J Biol Chem. 2012;287:4260-74. https://doi.org/10.1074/jbc.M111. 304311.

49. Caymaris $\mathrm{S}$, et al. The global nutritional regulator CodY is an essential protein in the human pathogen Streptococcus pneumoniae. Mol Microbiol. 2010;78:344-60.

50. Basavanna $S$, et al. The effects of methionine acquisition and synthesis on Streptococcus pneumoniae growth and virulence. PloS ONE. 2013;8:e49638. https://doi.org/10.1371/journal.pone. 0049638.

51. Saleh M, et al. Molecular architecture of Streptococcus pneumoniae surface thioredoxin-fold lipoproteins crucial for extracellular oxidative stress resistance and maintenance of virulence. EMBO Mol Med. 2013;5:1852-70. https://doi.org/10.1002/emmm. 201202435

52. Dengler V, et al. Mutation in the C-di-AMP cyclase dacA affects fitness and resistance of methicillin resistant Staphylococcus aureus. PloS ONE. 2013;8:e73512. https://doi.org/10.1371/journa 1.pone. 0073512 .

53. Dörries K, Schlueter R, Lalk M. Impact of antibiotics with various target sites on the metabolome of Staphylococcus aureus. Antimicrob Agents Chemother. 2014;58:7151-63. https://doi.org/10. 1128/AAC.03104-14.

54. Kanehisa M, et al. Data, information, knowledge and principle. Back to metabolism in KEGG. Nucleic Acids Res. 2014;42: D199-205. https://doi.org/10.1093/nar/gkt1076.

55. Foley S, et al. Characterisation of glutamine fructose-6-phosphate amidotransferase (EC 2.6.1.16) and $\mathrm{N}$-acetylglucosamine metabolism in Bifidobacterium. Arch Microbiol. 2008;189:157-67. https://doi.org/10.1007/s00203-007-0307-9.

56. Lee SH, et al. Antagonism of chemical genetic interaction networks resensitize MRSA to $\beta$-lactam antibiotics. Chem Biol. 2011;18:1379-89. https://doi.org/10.1016/j.chembiol.2011.08. 015 .

57. Zapun A, et al. In vitro reconstitution of peptidoglycan assembly from the Gram-positive pathogen Streptococcus pneumoniae. ACS Chem Biol. 2013;8:2688-96. https://doi.org/ $10.1021 / \mathrm{cb} 400575 \mathrm{t}$.

58. LeFrock JL, Prince RA, Leff RD. Mechanism of action, antimicrobial activity, pharmacology, adverse effects, and clinical efficacy of cefotaxime. Pharmacotherapy. 1982;2:174-84.

59. Mouz N, et al. Mutations in the active site of penicillin-binding protein PBP2x from Streptococcus pneumoniae. Role in the 
specificity for beta-lactam antibiotics. J Biol Chem. 1999;274: 19175-80.

60. Gordon E, Mouz N, Duée E, Dideberg O. The crystal structure of the penicillin-binding protein $2 x$ from Streptococcus pneumoniae and its acyl-enzyme form. Implication in drug resistance. J Mol Biol. 2000;299:477-85. https://doi.org/10.1006/jmbi.2000.3740.

61. Hoyer J, et al. Proteomic response of Streptococcus pneumoniae to iron limitation. Int J Med Microbiol. 2018;308:713-21. https:// doi.org/10.1016/j.ijmm.2018.02.001.

62. Aslim B, Calişkan F, Beyatli Y, Gündüz U. Poly-betahydroxybutyrate production by lactic acid bacteria. FEMS Microbiol Lett. 1998;159:293-7. https://doi.org/10.1111/j.15746968.1998.tb12874.x.

63. Lieberman D, et al. Multiple pathogens in adult patients admitted with community-acquired pneumonia. A one year prospective study of 346 consecutive patients. Thorax. 1996;51:179-84.

64. Kaul R, et al. Intravenous immunoglobulin therapy for streptococcal toxic shock syndrome - a comparative observational study. The Canadian Streptococcal Study Group. Clin Infect Dis. 1999;28:800-7. https://doi.org/10.1086/515199.

65. Schroeder MR, Stephens DS. Macrolide resistance in Streptococcus pneumoniae. Front Cell Infect Microbiol. 2016;6:98. https://doi.org/10.3389/fcimb.2016.00098.

66. Ambrose KD, Nisbet R, Stephens DS. Macrolide efflux in Streptococcus pneumoniae is mediated by a dual efflux pump (mel and mef) and is erythromycin inducible. Antimicrob Agents Chemother. 2005;49:4203-9. https://doi.org/10.1128/AAC.49.10. 4203-4209.2005.

67. Nunez-Samudio V, Chesneau O. Functional interplay between the ATP binding cassette $\mathrm{Msr}(\mathrm{D})$ protein and the membrane facilitator superfamily $\operatorname{Mef}(\mathrm{E})$ transporter for macrolide resistance in Escherichia coli. Res Microbiol. 2013;164:226-35. https://doi.org/ 10.1016/j.resmic.2012.12.003.

68. Chancey ST, Zhou X, Zähner D, Stephens DS. Induction of efflux-mediated macrolide resistance in Streptococcus pneumoniae. Antimicrob Agents Chemother. 2011;55:3413-22. https:// doi.org/10.1128/AAC.00060-11.

69. Cirz RT, et al. Complete and SOS-mediated response of Staphylococcus aureus to the antibiotic ciprofloxacin. J Bacteriol. 2007;189:531-9. https://doi.org/10.1128/JB.01464-06.

70. Zitka O, et al. Redox status expressed as GSH:GSSG ratio as a marker for oxidative stress in paediatric tumour patients. Oncol Lett. 2012;4:1247-53. https://doi.org/10.3892/ol.2012.931.

71. Brito L, et al. Absence of tmRNA has a protective effect against fluoroquinolones in Streptococcus pneumoniae. Front Microbiol. 2016;7:2164. https://doi.org/10.3389/fmicb.2016.02164.

72. Ferrándiz M-J, La Campa AGde. The fluoroquinolone levofloxacin triggers the transcriptional activation of iron transport genes that contribute to cell death in Streptococcus pneumoniae.
Antimicrob Agents Chemother. 2014;58:247-57. https://doi.org/ 10.1128/AAC.01706-13.

73. Higgins ML, Daneo-Moore L, Boothby D, Shockman GD. Effect of inhibition of deoxyribonucleic acid and protein synthesis on the direction of cell wall growth in Streptococcus faecalis. J Bacteriol. 1974;118:681-92.

74. Zong Y, et al. Gram-scale total synthesis of teixobactin promoting binding mode study and discovery of more potent antibiotics. Nat Commun. 2019;10:3268. https://doi.org/10.1038/s41467-01911211-y.

75. Monaim SAHA, et al. Investigation of the N-terminus amino function of Arg10-Teixobactin. Molecules. 2017;22. https://doi. org/10.3390/molecules22101632.

76. Chugunov A, et al. Lipid-II forms potential "landing terrain" for lantibiotics in simulated bacterial membrane. Sci Rep. 2013;3:1678. https://doi.org/10.1038/srep01678.

77. Liu Y, Liu Y, Chan-Park MB, Mu Y. Binding modes of teixobactin to lipid ii. molecular dynamics study. Sci Rep. 2017;7:17197. https://doi.org/10.1038/s41598-017-17606-5.

78. Homma T, et al. Dual targeting of cell wall precursors by teixobactin leads to cell lysis. Antimicrob Agents Chemother. 2016;60:6510-7. https://doi.org/10.1128/AAC.01050-16.

79. Schulz C, et al. Regulation of the arginine deiminase system by ArgR2 interferes with arginine metabolism and fitness of Streptococcus pneumoniae. mBio. 2014;5. https://doi.org/10.1128/ mBio.01858-14.

80. Gupta R, et al. Deletion of arcD in Streptococcus pneumoniae D39 impairs its capsule and attenuates virulence. Infect Immun. 2013;81:3903-11. https://doi.org/10.1128/IAI.00778-13.

81. Hyams C, Camberlein E, Cohen JM, Bax K, Brown JS. The Streptococcus pneumoniae capsule inhibits complement activity and neutrophil phagocytosis by multiple mechanisms. Infect Immun. 2010;78:704-15. https://doi.org/10.1128/IAI.00881-09.

82. Kilstrup M, Hammer $K$, Ruhdal Jensen $P$, Martinussen J. Nucleotide metabolism and its control in lactic acid bacteria. FEMS Microbiol Rev. 2005;29:555-90. https://doi.org/10.1016/j. fmrre.2005.04.006.

83. Carvalho SM, et al. Pyruvate oxidase influences the sugar utilization pattern and capsule production in Streptococcus pneumoniae. PloS ONE. 2013;8:e68277. https://doi.org/10.1371/journal. pone.0068277.

84. Carvalho SM, Kuipers OP, Neves AR. Environmental and nutritional factors that affect growth and metabolism of the pneumococcal serotype 2 strain D39 and its nonencapsulated derivative strain R6. PloS ONE. 2013;8:e58492. https://doi.org/10.1371/ journal.pone.0058492.

85. Carvalho SM, et al. Interplay between capsule expression and uracil metabolism in Streptococcus pneumoniae D39. Front Microbiol. 2018;9:321. https://doi.org/10.3389/fmicb.2018.00321. 